\title{
Flash flaming technology shows promise to improve seed-based rehabilitation outcomes
}

\author{
E Ling The University of Western Australia, Australia
}

AL Guzzomi The University of Western Australia, Australia

DJ Merritt Department of Biodiversity, Conservation and Attractions, Australia

M Renton The University of Western Australia, Australia

TE Erickson The University of Western Australia, Australia

\begin{abstract}
The success of mine site rehabilitation using native seeds is hampered by poor seedling establishment. Seed enhancement treatments including seed coatings and pelleting form one strategy to improve establishment. However, for some seeds, particularly those of grasses, irregular shapes and surface features of covering floret structures are difficult to remove at commercial scales and these features hinder both the polymer seed coating process and the 'flowability' of material through mechanical sowing equipment. A flash flaming technique has recently been developed which effectively removes these surface features from Triodia (spinifex) florets. Tests show flaming imparts a significant volume reduction in seed collections, increases the bulk density, and improves the 'flowability' of treated florets, with little to no alteration to the viability of seeds. Current work is extending the application of flaming to additional genera with problematic features including those of Ptilotus, Cymbopogon, Eriachne, Stirlingia, Chloris, Rytidosperma, and Gomphrena. Different methods of flash flaming are being investigated to determine the optimum settings for each species to achieve a balance in 'flowability', seed survivability, and improvement in floret volume and bulk density. Future work is aimed at further improving the flash flaming method and testing the flow of treated seed material through commercial-scale seeding machinery.
\end{abstract}

Keywords: mine site rehabilitation, direct seeding, flash flaming, commercial-scale, 'flowability', volume reduction, bulk density

\section{Introduction}

Extraction of mineral resources through mining disturbs large areas of land in the arid and semi-arid zones of Western Australia. At most mine sites, there is a deficit of stockpiled topsoil that means that the direct sowing of wild native seeds becomes the primary method for large-scale mine site rehabilitation (Merritt \& Dixon 2011). Yet significant gaps in seed handling and precision delivery still limit the recruitment potential and efficiency of use of native seeds. One area of interest to investigate seed-use inefficiencies is the Pilbara region of Western Australia, where about 2,300 $\mathrm{km}^{2}$ of land has been approved for mining and related activities (Environmental Protection Authority 2014). The cumulative area approved for clearing is expected to increase to over $4,500 \mathrm{~km}^{2}$ following the approval of future mining in the Pilbara. The flora of the Pilbara region is dominated by grasses from genera such as Triodia (spinifex), Cymbopogon, Eriachne, and Aristida, with other common genera including Ptilotus and Gomphrena. For instance, Triodia (spinifex) grasslands cover up to $25 \%$ of the inland Australia (Erickson et al. 2016a, 2016b) and are a crucial element in mine site rehabilitation.

Currently there are limitations to the efficiency of direct seeding for rehabilitation in arid regions, and it is common for a small proportion of seeds (i.e. <5\%) to establish (Hardegree et al. 2016; Saatkamp et al. 2019). Factors influencing seedling establishment include the dormancy status and germination capacity of the seeds (Gibson-Roy et al. 2010), which can be difficult to control or require an extensive knowledge base to 
promote recruitment (Erickson et al. 2017). Seed enhancement technologies aim to improve the effectiveness of direct seeding and reduce the seed mortality during early plant life-stage transitions. Examples of such technologies are priming, the application of polymer seed coatings, and the development of clay-based extruded seed pellets and agglomerates (Guzzomi et al. 2016; Madsen et al. 2012; Abella et al. 2015; Merritt et al. 2016). Polymer seed coating is of particular interest for direct seeding as it improves the geometry of the seeds to improve their 'flowability' through mechanised seed processing units and enables better precision (Guzzomi et al. 2016).

Many native species found in the Pilbara region of Western Australia produce seeds that are contained within florets, and/or possess appendages such as awns and hairs. These appendages are bulky and prone to tangling, which hinders the 'flowability' through mechanical seeding machines. Studies on rice florets have found that de-awning not only improves their 'flowability' through a horizontal hopper orifice (Alizadeh et al. 2012) but also reduces the cohesiveness between them (Alizadeh \& Minaei 2012) and increases the bulk density by 66 to $72 \%$ (Alizadeh et al. 2012). However, de-awning techniques, such as using hammer mills and hand rubbing, are highly dependent on the operator (Gregg \& Billups 2010) and have very low seed processing rates (Loch 1993) for large-scale land seeding efforts.

Through a collaboration between Kings Park Science and The University of Western Australia (UWA), a flash flaming technology was developed and patented (Guzzomi et al. 2016). This technology provides a feasible large-scale alternative to de-awning. The technology introduces stationary flaming devices into a traditional seed-coating drum. The drum imparts rotary motion onto the florets or seeds and through continuously flaming of the rotating stream, the appendages are removed or reduced. The motion ensures that the florets are repeatedly exposed to brief bursts of heat energy through the flame which, combined with the agitation of the mixing bars, encourages uniform flaming of florets without damaging the seeds. The flash flaming technique has been shown to increase the bulk density, 'flowability', and 'coatability' of Triodia wiseana florets at small scales (Guzzomi et al. 2016). For instance, $60 \mathrm{sec}$ of flash flaming reduced the appendages on the florets to a smooth surface, suitable for coating, and achieved more than a $40 \%$ increase in bulk density and a $36 \%$ decrease in weight (Guzzomi et al. 2016).

However, as that initial work used a small-scale prototype, only small quantities of florets were treated. For broader adoption in the rehabilitation seeding industries, it must be demonstrated that the flaming can be successfully applied to larger volumes of florets or seeds of diverse species of interest. Thus, larger scale flash flaming trials are investigating the scalability of flash flaming. This paper describes the outcomes of some of these trials, in conjunction with investigations to quantify the effects of the flaming period on the changes in volume, bulk density and 'flowability' using lab-based assessments, and germination tests to investigate the post-flamed germination capability of the florets.

\section{$2 \quad$ Materials and methods}

\section{$2.1 \quad$ Florets}

Evaluating a wider range of species using flash flaming is a crucial element in the commercial uptake of such technologies and a key element of large-scale, diverse seed-use. To investigate the effect of flash flaming on various wild native species, tests have been carried out on wild native grass species including Triodia pungens, $T$. wiseana, $T$. basedowii, $T$. lanigera, $T$. vanleeuwenii, and $T$. epactia. To ensure commercial-scale quantities of floret material were tested, $3 \mathrm{~L}$ samples for each species were used for each flaming trial.

\section{$2.2 \quad$ Equipment}

To accommodate a greater volume of floret material, a larger flash flaming machine was designed and built. This flash flaming machine was based on the same working principle as the first prototype. The Seed Flamer MK I, as indicated in Figure 1, is the first generation of the flash flaming machine and was used to conduct flash flaming on the targeted species listed in Section 2.1. The team is now constructing the Seed Flamer 
MK II and MK III, which includes more advanced functionality such as a pneumatic door, auto ignition trigger for the torches, improved monitoring systems, and improved ergonomics and drive system.

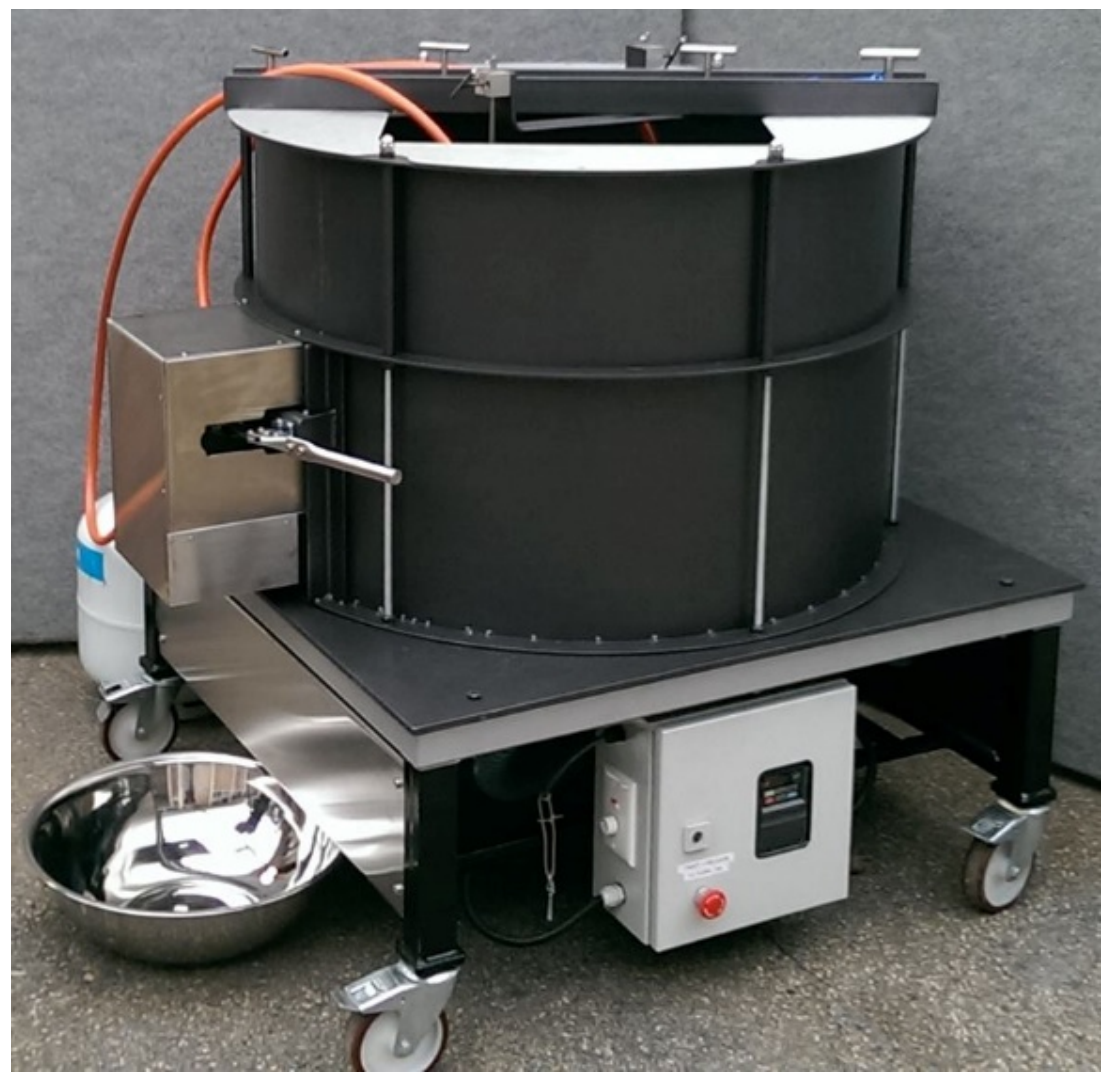

Figure 1 MK I seed flamer comprises a conventional drum seed coater with two flame torches, propane gas cylinder, and a control panel

\subsection{Tests conducted}

'Flowability' describes the tendency of blockage, attrition, and segregation of substances such as powders or discrete substances in a flowing situation caused by the cohesiveness between the particles (Geldart et al. 2006). The Hausner ratio (HR) and the angle of repose (AOR) were used to quantify the 'flowability' of florets prior and after flaming. Germination tests were carried out after flaming to ensure no significant viability loss of seed material (encased within the florets) occurred.

\subsubsection{Flash flaming test}

Different flame torches were used to deliver different sizes of flame. The size of the flame is determined by the gas consumption in $\mathrm{g} / \mathrm{hr}$. The 'soft' flame burner (gas consumption rate of 1,200 $\mathrm{g} / \mathrm{hr}$ ) delivers a broader, larger volume flame zone and the 'trade' flame delivers a precise, triangular-tipped small flame (gas consumption rate of $295 \mathrm{~g} / \mathrm{hr}$ ).

Due to the multiple variables that can influence the optimum outcomes of the experiment, and to ensure each variable was accounted for, the order of the experiment for each species was based on two scenarios: one by changing the flame type (Figure 2(a)) and another by changing the flame time (Figure 2(b)). The percentage of germination before and after flaming was used as an indicator to determine which scenario to adopt for additional trials. For example, if the seeds failed to germinate or if the overall germination percentage declined when compared to the untreated seeds, the type of flame torch was changed (Figure 2(a)). Under this scenario, if the germination remains unchanged or increases, the experiment continued to investigate the effects of flaming on changes in volume, bulk density, 'flowability' and germination in relation to flaming time. If the florets/seeds still failed to germinate after changing the type of flame, the flame time was adjusted without changing the type of flame torch (Figure 2(b)). 


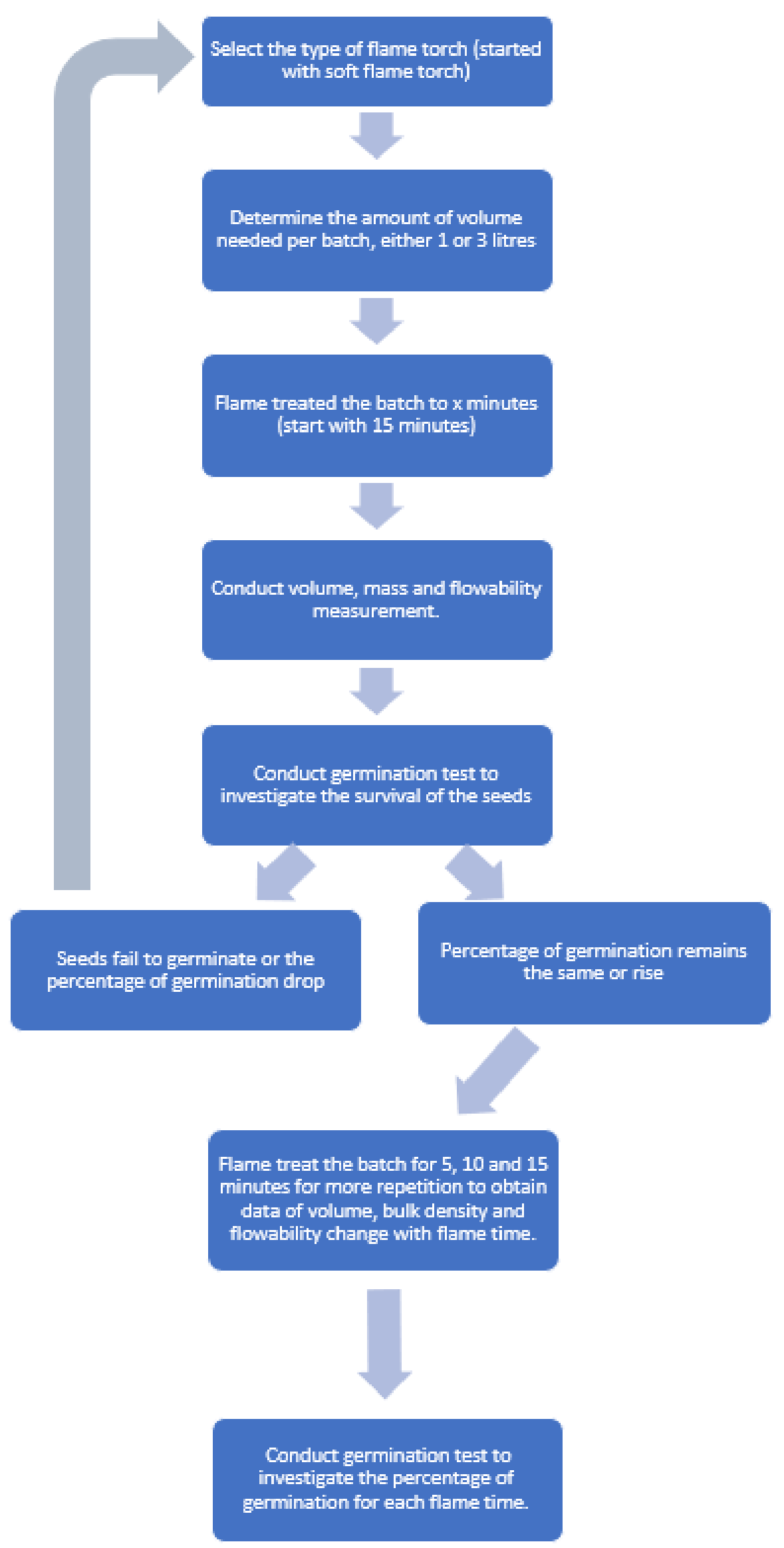

(a) 


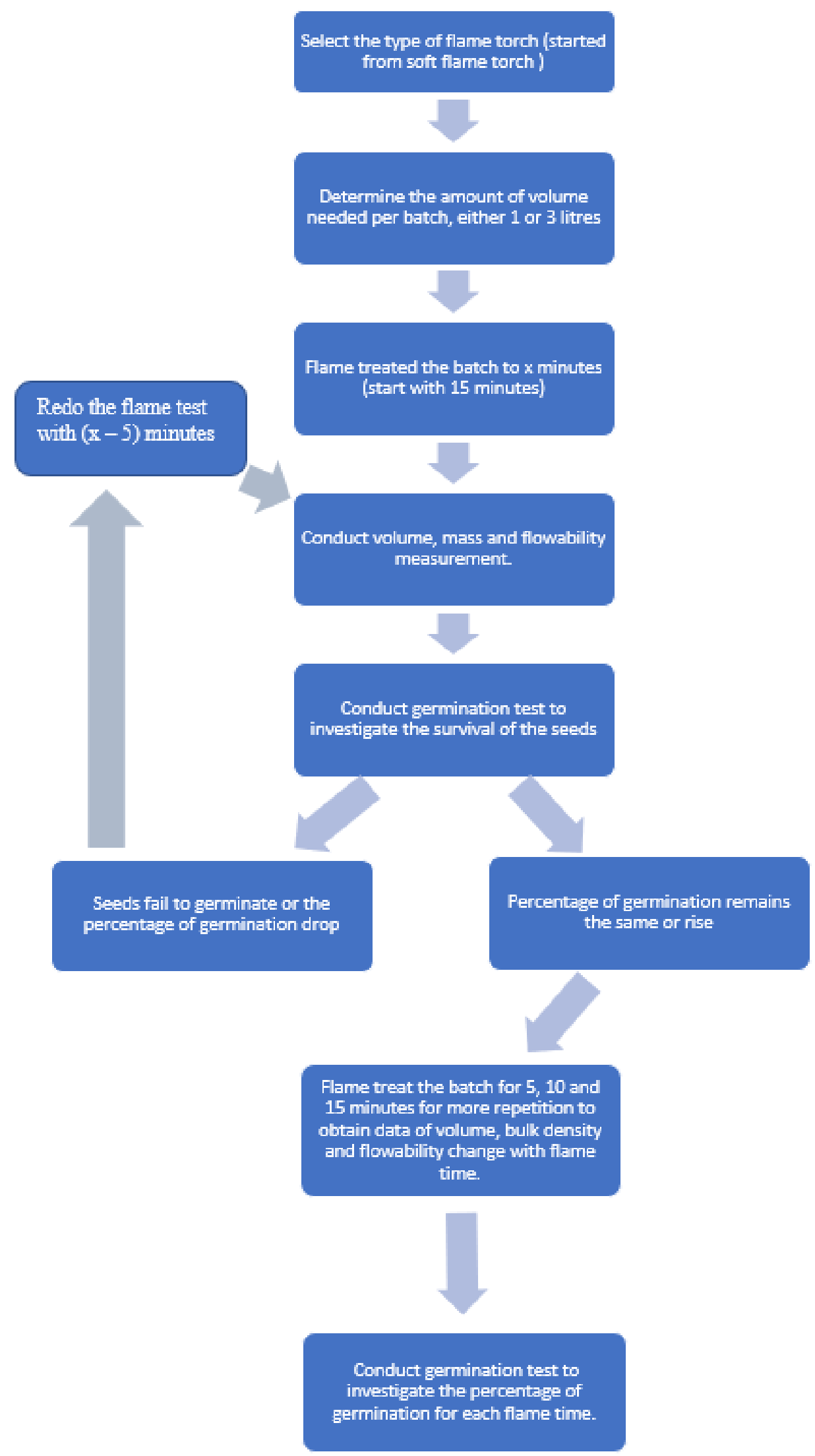

(b)

Figure 2 (a) Scenario one involves the change of the type of flame torch; (b) scenario two involves the change in flame time 


\subsubsection{Quantifying 'flowability': Hausner ratio}

The HR uses bulk density measurements as 'flowability' indicators and is commonly used for granular material (Hausner 1967; Grey \& Beddow 1969). It is the ratio of the tapped bulk density and the aerated bulk density. The bulk volume occupied by the particles includes the voids between the particles and the volume of the particles themselves (Abdullah \& Geldart 1999). The bulk density is a function of how much the particles are packed (Abdullah \& Geldart 1999). Both aerated bulk density and tapped bulk density have to be evaluated to obtain the HR. A drop in the HR from 1.25 indicates a decrease in cohesiveness of granular material (Dutta \& Dullea 1990) and increase in 'flowability'.

The aerated bulk density of granular material is obtained from loosely packed particles which can settle in a container under the effect of gravity (Abdullah \& Geldart 1999). Abdullah \& Geldart (1999) detailed that the aerated bulk density can be obtained by pouring powder through a vibrating sieve into a $100 \mathrm{ml}$ cup in no less than $30 \mathrm{sec}$. The tapped bulk density is obtained from the densely-packed particles. This is achieved by providing 180 taps over a period of six min on the container which contains the aerated granular material (Abdullah \& Geldart 1999).

Hausner (1967) found that the further the particles' shape differs from spherical, the higher the ratio of tapped to aerated density, indicating poorer 'flowability'. This finding was supported by Zou \& Yu (1996) in which the HR decreased with the increase of sphericity, which indicating increased 'flowability'. Quantitatively, the HR is categorised into low cohesive, easy-to-flow (group A) and highly cohesive, difficultto-flow (group C) (Geldart et al. 2006). Group C exhibits a HR greater than 1.4 and group A exhibits a HR less than 1.25. HR drops between 1.25 and 1.4 are categorised as a transitional group (group AC) and exhibit a semi-cohesive property (Abdullah \& Geldart 1999; Geldart et al. 2006). An important concept to take note is that the HR reflects the dynamic friction condition in a moving mass of powder or granular material rather than in a static situation (Abdullah \& Geldart 1999).

We adopted the use of the HR to characterise floret flow rates prior to and after flaming. In this study, the aerated volume was obtained by pouring the florets gently into a measuring cylinder and let them settle without tapping or altering the position of the measuring cylinder. For tapped volume, several tapping trials are carried out to determine the number of taps required for the six Triodia species. The tapping was conducted by compressing the florets within a measuring cylinder using a flat bottom disk until the florets can no longer compressed. This indicates that the voids between the florets have been filled. Sixty taps were sufficient to achieve the required outcome.

\subsubsection{Quantifying 'flowability': angle of repose}

The AOR can be determined by various methods that apply only to free-flowing powder or granular material (Podczeck \& Jones 2004). The results can differ depending on the operator and method used (Podczeck \& Jones 2004; Geldart et al. 2006). These methods are fixed height cone method, fixed based cone methods, using tilting table, or a rotating cylinder.

To help minimise operator-induced errors and increase repeatability, techniques were developed to allow the florets to flow and form a semi-cone in which the height and radius can be read from the scales. This technique was adopted in this study by using a fix height hopper, a wall marked with a chosen height of $7 \mathrm{~cm}$ and a graph paper with $1 \mathrm{~cm}^{2}$ grid size (Figure 3). The florets were poured gently from the hopper onto the wall to form a semi-cone shape profile until the height reached $7 \mathrm{~cm}$. The radius of the semi-cone, furthest from the wall, can be read from the graph paper. From there, the AOR can be determined. Carr $(1965,1970)$ suggested that angles of repose below $30^{\circ}$ indicated good 'flowability'. Angles of repose between 30 and $45^{\circ}$ indicate semi-cohesiveness. Angles of repose between 45 and $55^{\circ}$ indicate some cohesiveness. Angles of repose greater than $55^{\circ}$ indicate very high cohesiveness (Geldart et al. 2006). High cohesiveness indicates very poor 'flowability'. 


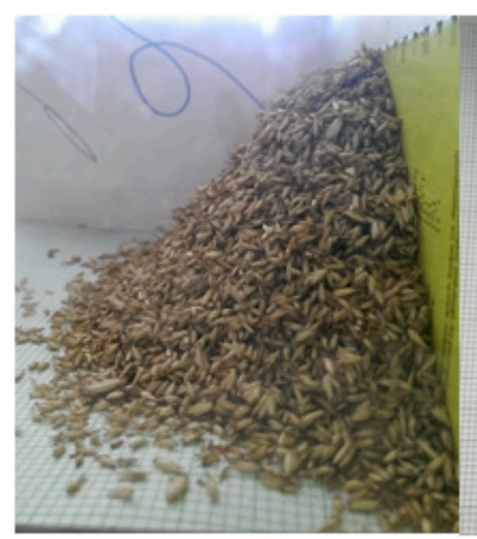

(a)

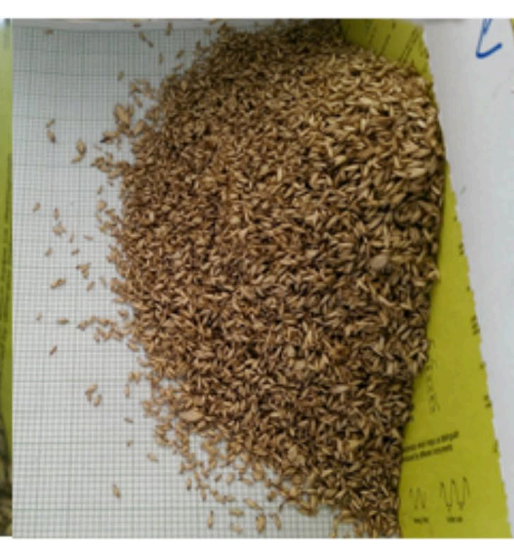

(b)

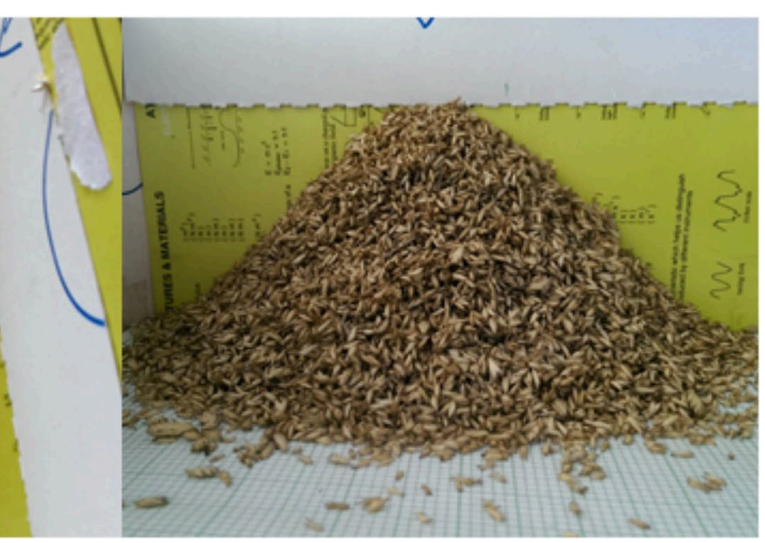

(c)

Figure 3 Setup of the experiment to evaluate angle of repose. (a) Side view; (b) top view; (c) front view of the semi-cone shape florets profile. The top white boundary at (c) indicates a height of $7 \mathrm{~cm}$. The graph paper used in this experiment has grid size of $1 \mathrm{~cm}^{2}$

\subsubsection{Germination test}

The germination test in this study followed the germination test performed by Guzzomi et al. (2016). Three litres of Triodia florets were flash flamed for 2, 4, 6, 8, and $10 \mathrm{~min}$. Untreated florets (no flaming) were used as the control. After flash flaming, the florets were X-rayed to identify the florets that contained seeds. Four replicates of 25 seed-filled florets were placed on petri dishes containing water or containing the germination stimulant karrikinolide $\left(\mathrm{KAR}_{1}\right)$. The petri dishes were incubated at constant $25^{\circ} \mathrm{C}$ under a $12 \mathrm{~h} / 12 \mathrm{~h}$ light/dark cycle for two weeks. Germination was defined as emergence of radicle to a length greater than one-third of the length of the florets (Erickson et al. 2016b) and was assessed once weekly for two weeks.

\section{Results and discussion}

\subsection{Volume, bulk density, and germination}

Florets of all six Triodia species displayed decreases in volume and weight following flaming (Table 1). Florets of Triodia pungens showed a relatively insignificant reduction in volume, weight, and increase in bulk density. This was largely due to the lack of bulky appendages on Triodia pungens florets as compared to the other Triodia species. The result indicates that flash flaming technology is scalable and the bigger drum is able to accommodate more florets. Optimum flame treatment is determined by the volume reduction, the increase in bulk density and 'flowability', and maintenance of germination potential. Flash flaming is considered a success when the resulting florets achieved reduction in volume, increase in bulk density and 'flowability' without causing more than a 50\% decrease in germination. The summarised results in Table 1 depicts the optimum flame treatment based on these criteria. Tests conducted show that 10 min of flash flaming is enough to achieve volume reduction, an increase in bulk density, and reach desirable 'flowability' without damaging the seeds within the florets. Due to the short supply of Triodia vanleeuwenii and Triodia epactia, these species were flame tested using the 'light fraction' after vacuum aspiration, that is, florets without seeds and was not tested for germination. Both Triodia vanleeuwenii and Triodia epactia achieved optimum volume reduction, increase in bulk density and 'flowability' after 15 min of flaming.

In terms of 'flowability', florets of all of the six Triodia species fell below 1.25 in HR and within the range of semi-cohesiveness in the AOR measurement (Table 1). Germination results were carried out on Triodia pungens, Triodia wiseana, Triodia basedowii, and Triodia lanigera. From the results, apart from Triodia pungens which showed decrease in germination, the other tested species showed increases in germination (Table 1). 
Table 1 Flash flaming results of Triodia pungens, T.wiseana, T.basedowii and T.lanigera after $10 \mathrm{~min}$ of flaming and light fraction of T. vanleeuwenii and T. epactia after 15 min of flaming

\begin{tabular}{lllllll}
\hline Triodia species & $\begin{array}{l}\text { Volume } \\
\text { reduction } \\
\text { (\%) }\end{array}$ & $\begin{array}{l}\text { Weight } \\
\text { reduction } \\
\text { (\%) }\end{array}$ & $\begin{array}{l}\text { Increase } \\
\text { in bulk } \\
\text { density } \\
\text { (\%) }\end{array}$ & $\begin{array}{l}\text { Hausner Ratio } \\
\text { (control vs } \\
\text { flaming } \\
\text { treatment) }\end{array}$ & $\begin{array}{l}\text { Angle of } \\
\text { repose } \\
\text { (control vs } \\
\text { flaming } \\
\text { treatment } \\
\text { [']) }\end{array}$ & $\begin{array}{l}\text { Germination } \\
\text { of florets } \\
\text { (control vs } \\
\text { flaming } \\
\text { treatment } \\
\text { [\%]) }\end{array}$ \\
\hline T. pungens & 13.3 & 11.5 & 2.20 & 1.25 vs 1.08 & 36 vs 30.5 & 72 vs 58 \\
T. wiseana & 20.0 & 8.50 & 14.4 & 1.53 vs 1.11 & 47.1 vs 34.7 & 52 vs 58 \\
T. basedowii & 38.3 & 14.8 & 38.1 & 1.66 vs 1.25 & 43.4 vs 37.9 & 33 vs 52 \\
T. lanigera & 51.7 & 17.1 & 71.4 & 1.84 vs 1.15 & 48.4 vs 36.1 & 38 vs 34 \\
T. vanleeuwenii & 33.3 & 16.4 & 25.3 & 1.33 vs 1.11 & 41.2 vs 34.7 & - \\
T. epactia & 18.3 & 9.40 & 10.9 & 1.33 vs 1.08 & 41.9 vs 34.4 & - \\
\hline
\end{tabular}

\subsection{Geometry of the florets}

Figure 4 shows the change in the geometry and the 'coatability' of $T$. wiseana florets after flash flaming treatment application. Before flash flaming, the florets were not equally coated. After flash flaming, the florets, having a more spherical shape, were able to be coated more uniformly. There was insignificant removal of appendages between 15 and 20 min of flaming.

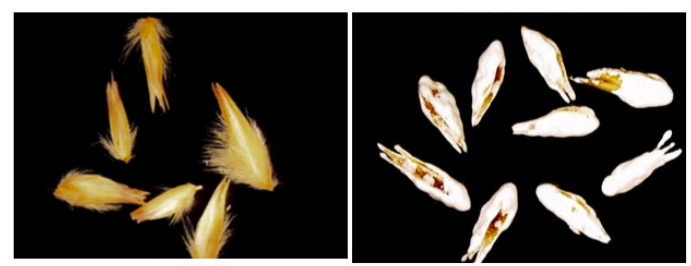

(A) Control

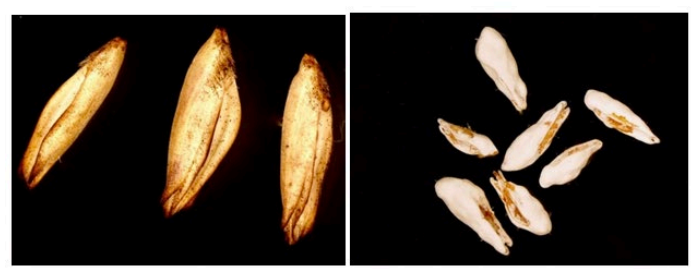

(B) 10 minutes flaming

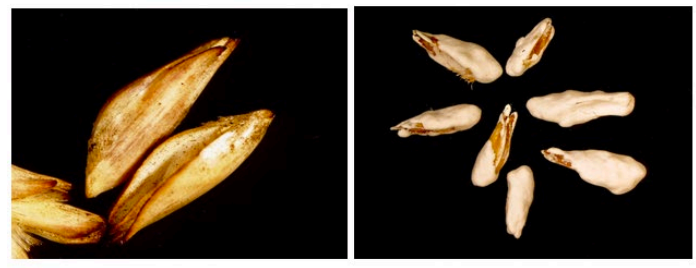

(C) 15 minutes flaming
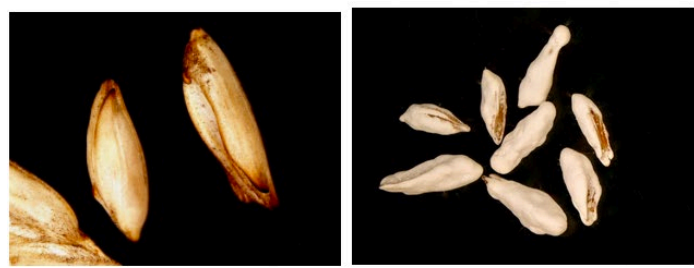

Figure 4 The effect of flash flaming on Triodia wiseana florets in terms of the change in geometry (left) and 'coatability' (right). The florets were flamed for 10, 15, or $20 \mathrm{~min}$ 


\section{Conclusion}

This study shows that flash flaming technology is not only scalable, but also has the potential to become an alternative seed management option in mine site rehabilitation programs. Flash flaming enhances the florets by improving the geometry, increasing storage capability, 'flowability' and 'coatability'. It is likely that these improvements will facilitate increased mechanisation and seed-use efficiency.

Future work is now carrying out these evaluations on a range of species that are in demand for mining, as well as for post-agricultural seeding programs in the southwest regions of Western Australia (namely species from genera such as Ptilotus, Cymbopogon, Eriachne, Stirlingia, Chloris, Rytidosperma, and Gomphrena).

\section{Acknowledgement}

This study was supported by a BHP Western Australia Iron Ore (BHPWAIO) Community Development Project (contract no. 8600048550) under the auspices of Restoration Seedbank Initiative, a partnership between BHPWAIO, the UWA and the Botanic Gardens and Parks Authority and the Global Innovation Linkages project grant (GIL53873) titled Eco-Engineering Solutions to Improve Mine-Site Rehabilitation Outcomes funded by the Department of Industry, Innovation and Science. The authors are grateful to the UWA mechanical workshop technicians, Matt Alphin, Mark Henderson, and Joss Doak-Smith, and electrical workshop technicians, Gerald Wright and Andrew Parton, for their workmanship and craftmanship.

\section{References}

Abdullah, E \& Geldart, D 1999, 'The use of bulk density measurements as 'flowability' indicators', Powder Technology, vol. 102(2), pp. 151-165.

Abella, S, Chiquoine, L, Engel, C, Kleinick, K \& Edwards, F 2015, 'Enhancing quality of desert tortoise habitat: augmenting native forage and cover plants', Journal of Fish and Wildlife Management, vol. 6, pp. 278-289.

Alizadeh, MR, Minaei, S, Rahimi-Ajdadi, F, Tavakoli, T, Khoshtaghaza, MH \& Zareiforoush, H 2012, ‘Flow properties of awned and de-awned paddy grains through a horizontal hopper orifice', Particulate Science and Technology, vol. 30, pp. 343-353.

Alizadeh, M \& Minaei, S 2012, 'Effect of de-awning and moisture content on some frictional properties of paddy', Journal of Food Process Engineering, vol. 35, pp. 471-482.

Carr, RL 1965, 'Classifying flow properties of solids', Chemical Engineering, vol. 1, pp. 69-72.

Carr, RL 1970, 'Particle behaviour, storage and flow', British Chemical Engineering, vol. 15(12), pp. 1541-1549.

Dutta, A \& Dullea, LV 1990, 'A comparative evaluation of negatively and positively charged submicron particles as flow conditioners for a cohesive powder', AIChE Symposium Series, vol. 86, issue 276, pp. 26-40.

Erickson, TE, Barrett, RL, Merritt, DJ \& Dixon, KW 2016a, Pilbara Seed Atlas and Field Guide: Plant Restoration in Australia's Arid Northwest, CSIRO Publishing, Dickson.

Erickson, TE, Shackelford, N, Dixon, KW, Turner, SR \& Merritt, DJ 2016b, 'Overcoming physiological dormancy in seeds of Triodia (Poaceae) to improve restoration in the arid zone', Restoration Ecology, vol. 24, S64-S76.

Erickson, TE, Munoz-Rojas, M, Kildisheva, OA, Stokes, BA, White, SA, Heyes, JL, ... Merritt, DJ 2017, 'Benefits of adopting seed-based technologies for rehabilitation in the mining sector: a Pilbara perspective', Australian Journal of Botany, vol. 65, 646-660.

Environmental Protection Authority 2014, Cumulative Environmental Impacts of Development in the Pilbara Region, Government of Western Australia.

Geldart, D, Abdullah, E, Hassanpour, A, Nwoke, L \& Wouters, I 2006, 'Characterization of powder 'flowability' using measurement of angle of repose', ChinaParticuology, vol. 4(3-4), pp. 104-107.

Gibson-Roy, P, Moore, G, Delpratt, J \& Gardner, J 2010, 'Expanding horizons for herbaceous ecosystem restoration: the Grassy Groundcover Rehabilitation Project', Ecological Management and Restoration, vol. 11, pp. 176-186.

Gregg, B \& Billups, G 2010, Seed conditioning: volume 2, technology-part A, CRC Press, Enfield.

Grey, RO \& Beddow, JK 1969, 'On the Hausner ratio and its relationship to some properties of metal powders', Powder Technology, vol. 2(6), pp. 323-326.

Guzzomi, A, Erickson, T, Ling, K, Dixon, K \& Merritt, D 2016, 'Flash flaming effectively removes appendages and improves the seed coating potential of grass florets', Restoration Ecology, vol. 24, S98-S105.

Hardegree, SP, Jones, TA, Roundy, BA, Shaw, NL \& Monaco, TA 2016, 'Assessment of range planting as a conservation practice' Rangeland Ecology \& Management, vol. 69, pp. 237-247.

Hausner, HH 1967, 'Friction conditions in a mass of metal powder', Polytechnic Institute of Brooklyn, University of California, Los Angeles.

Loch, DS 1993, 'Tropical pasture establishment, 5. Improved handling of chaffy grass seeds: options, opportunities and value', Tropical Grasslands, vol. 27, pp. 314-326.

Madsen, MD, Davies, KW, Williams, CJ \& Svejcar, TJ 2012, 'Agglomerating seeds to enhance native seedling emergence and growth', Journal of Applied Ecology, vol. 49, pp. 431-438. 
Merritt, DJ \& Dixon, KW 2011, 'Restoration seed banks - a matter of scale', Science, vol. 332, pp. 424-425.

Merritt, DJ, Golos, PJ \& Erickson, TE 2016, 'A systematic approach to seed management for restoration', in TE Erickson, RL Barrett, DJ Merritt \& KW Dixon (eds), Pilbara Seed Atlas and Field Guide: Plant Restoration in Australia's Arid Northwest, CSIRO Publishing, Dickson, pp. 35-42.

Podczeck, F \& Jones, BE 2004, Pharmaceutical capsules, Pharmaceutical Press, London.

Saatkamp, A, Cochrane, A, Commander, L, Guja, LK, Jimenez-Alfaro, B, Larson, J, ... Dalziell, EL 2019. 'A research agenda for seed-trait functional ecology', New Phytologist, vol. 221(4), pp. 1764-1775.

Zou, RP \& Yu, AB 1996, 'Evaluation of the packing characteristics of mono-sized non-spherical particles', Powder Technology, vol. 88(1), pp. 71-79. 